\title{
Nahçıvan Bölgesinin Erken Tunç Çağı Yerleşimlerinde Bulunan Pişmiş Toprak Objeler
}

\author{
Terracotta Objects Found in the Early Bronze Age Settlements of the Nakhchivan \\ Region
}

\section{Toğrul Halilov*}

\section{Öz}

Nahçıvan Özerk Cumhuriyeti topraklarında Erken Tunç Çağı'na ait birçok yerleşim yeri bulunmaktadır. Buralarda bulunan arkeolojik bulguların araştırılması, bu çağın işçiliğini ve tarım alanlarını, ekonomik ve kültürel ilişkilerini, insanların maddi ve manevi kültürünü derinden öğrenmek bakımından bize kolaylık sağlamaktadır. Yerleşimlerin her birinde, daha net bir şekilde araştırma yapıldığında önemli bilimsel veriler elde etmek mümkündür. Bu arkeolojik bulguların bir grubunu Erken Tunç Çağı'nın dairesel biçimli minyatür seramikleri oluşturmaktadır. Bu seramiklerin kulanım amacı ve yayılım alanı daha önceki yıllarda sistematik biçimde araştırılmadığından dolayı bu çalışmada tarafımızca incelenmiştir. Yürütülen bilimsel araştırma sonucu söz konusu seramiklerin tesadüfen yapılmadığı, belli bir amaç doğrultusunda yapıldıkları anlaşılmıştır.

\section{Anahtar Kelimeler}

Nahçıvan, Erken Tunç Çağı, Seramik, Araba kültürü, Objeler

\begin{abstract}
In the territory of the Nakhchivan Autonomous Republic, there are many archeological monuments belonging to the Early Bronze Age. As a result of the study of archaeological materials obtained from them, it is possible to study the craftsmanship, agricultural fields, economic and cultural relations, people's material and spiritual culture. From the ancient time, archaeological materials are of great importance in the study of our ancient history, material and spiritual culture. By studying each of them deeply, it is possible to achieve important scientific results. Some of such archaeological materials are circular shaped ceramics of the Early Bronze Age. They have been studied by us, since their functional character and the extent of their spread have not been studied in a complex form. It was discovered during the study that these archeological materials were not accidentally made, and they had a logical basis.
\end{abstract}

\section{Keywords}

Nakhchivan, Early Bronze Age, Ceramic, Car culture, Objects

* Sorumlu Yazar: Toğrul Halilov (Doç. Dr.), Azerbaycan Bilimler Akademisi, Nahçıvan Bölümü, Nahçıvan, Azerbaycan. E-posta: x.toqrul@gmail.com ORCID: 0000-0002-3703-8315

Atıf: Halilov, Togrul. "Nahçıvan Bölgesinin Erken Tunç Çağı Yerleşimlerinde Bulunan Pişmiş Toprak Objeler." Art-Sanat, 13 (2020): 189-203. https://doi.org/10.26650/artsanat.2020.13.0008 


\section{Extended Summary}

The culture of the early Bronze Age spread across a wide geographical area from the North Caucasus to Syria and Palestine. During the archeological research, the culture of the Early Bronze Age was given different names ("Red and Black Burnished Ware", "Khirbet Kerak / Beth Yerah", "Culture of Karaz", "Early Transcaucasian Culture", "Early Trans-Caucasian Culture and Eastern Anatolia Early Bronze Age") in the world. The Early Bronze Age archaeological culture of Azerbaijan is known as the Kura-Araz culture in publications. This occurs when the territory of the Nakhchivan culture was the Urmia region.

The Nakhchivan Autonomous Republic has a rich history. In the territory of the Nakhchivan Autonomous Republic, there are many archeological monuments belonging to the Early Bronze Age. As a result of the study of archaeological materials obtained from them, it is possible to study the craftsmanship, agricultural fields, economic and cultural relations, and people's material and spiritual culture. From the ancient time, archaeological materials are of great importance in the study of our ancient history, material and spiritual culture. By studying each of them deeply, it is possible to achieve important scientific results. Some of such archaeological materials are circular shaped ceramics of the Early Bronze Age. They have been studied by us, since their functional character and the extent of their spread have not been studied in a complex form. Some of such archaeological materials are clay wheel models of the Early Bronze Age. It was discovered during the study that these archeological materials were not accidentally made, and they had a logical basis.

Mahta I, Kultepe I, Kultepe II, Ovçular Tepesi settlements of this type of ceramic products were found. Their similarities have been found in the Telmankend, Baba Derviş, Valikend, Sarıtepe, Leylatepe, Büyük Kesik, Kalayeri, Poylu II, Polutepe, Mingachevir, Kobustan, Yanıktepe, Göytepe, Trialetti settlements, Anatolia, Altai and many parts of the world. In some of the Early Bronze Age settlements of Azerbaijan (Mingachevir, Kobustan), clay car figures were also found. The presence of miniature wheels and carts with settlements, as well as necropsy, proved that they were not made by chance, but had a certain logical meaning. When we look at history to prove our thoughts and miniature wheel of the car "running an animal culture", "Horseman car culture" and there are various information and resources about the build loyalty. Many researchers have different ideas about where the wheel was discovered firstly. The British archaeologists discovered the wheel for the first time, based on archaeological findings from their research on the Spencer and the Mesopotamia in the cave. They say that it was invented in the Mesopotamia in 5000 B.C. Researchers did not first discover that this archaeological material is a wheel. They considered that they were part of a potter's wheel to make clay pots. However, further research has revealed that these archeological materials are wheel. In addition to British archaeologists, many researchers have given various ideas about where the wheel and the cart were discovered 
firstly. After Spencer and Kavrada, the British researcher Volle conducted research on this subject. During his studies Mesopotamia was found a new wheel from 2950 BC.

According to some researchers, the wheel and cart were discovered in first time in the Van-Urmia region in the IV millennium B.C. They spread from this region to other parts of the world in the III-II millennium B.C. A group of researchers have stated that it was used by Turks in 2000-800 B.C. Mahmud of Kashgar "Divan-Lugati-it Turk" and Fazlullah Raşideddin work in the Oğuzname the information contained in the first cut since the car is being used has stated that by the Turks. Like in Mesopotamia, the history of the miniature wheel in Azerbaijan covers 5000 years. Numerous clay miniature wheels from the Chalcolithic Age (VI-IV millennium B.C) archaeological settlements of Polutepe, Leylatepe, Büyük Kesik, Kalayeri, Poylu II and Kültepe I were found. In all regions of the world, the discoveries of the wheel and the technical method have been the same. Until the wheel was discovered, people carried loads that were easy to carry on their backs and shoulders. Since they could not carry heavy loads on their shoulders and backs, they used various primitive technical methods that required a lot of labor and time. The discovery of the wheel created an environment for the discovery of the cart. The discovery of the cart had a major impact on people's lifestyle. In addition to horses, people were using ox carts and horses, in inter-crew economic-cultural relations, war and so on. As in all regions of the world, the formation process of the "Cart culture" started in Nakhchivan as a result of using the cart in various methods. In the history, the Turks used mostly the horse carriage. The use of horses by the Turks increased their freedom of movement, and created an environment for them to spread and have wider.

The circular, conical, cylindrical miniature ceramics found in the Early Bronze Age settlements of Nakhchivan (Mahta I, Kultepe I, Kultepe II) were made of clay with a mixture of fine and coarse sand. They made a group in a simple way. Some of them were drawn on geometric patterns. There is a wide range of information on the meaning of such archaeological findings. S. Lloyd, R. Mekkenem, H. Genouillac, D. MandtBessarat, L. Brun, F. Vallat, S. N. Bibikov, R. Munchaev, M. Jafarzadeh, S. Ashurov, V. Aliyev and other researchers designate these archeological materials have been various opinions about this. This type of ceramics is called "objects of uncertainty", "game pieces", "children's plaiting's". It is possible to see the same findings from the Nakhchivan, as well as from the settlements of Kobustan, Guzliktepe, Babadarvis and Ilantepe, as well as Azerbaijan during the research on the span of such findings. This type of archaeological findings were found in archaeological settlements such as Kizanantkora, Kunib, Luki-Vriblevetski, Yanıktepe, Ur and in many archaeological settlements belonging to the Ubayd culture in various parts of the world, as well as in Azerbaijan. Some of the specimens obtained from the archaeological settlements in Azerbaijan differ from the examples of the Ubayd culture according to their characteristics. 


\section{Giriş}

Nahçıvan Özerk Cumhuriyeti tarihsel bakımdan köklü bir geçmişe sahiptir. Nahçıvan Özerk Cumhuriyeti topraklarında Erken Tunç Çağı'na ait birçok yerleşim yeri bulunmaktadır. Buralarda bulunan arkeolojik bulguların araştırılması, bu çağın işçiliğini ve tarım alanlarını, ekonomik ve kültürel ilişkilerini, insanların maddi ve manevi kültürünü derinden öğrenmek bakımından bize kolaylık sağlar. Yerleşimlerin her birinde araştırma yapılmadığında önemli bilimsel veriler elde etmek mümkündür. $\mathrm{Bu}$ arkeolojik bulguların bir grubunu Erken Tunç Çağı'nın dairesel biçimli minyatür seramikleri oluşturmaktadır. Bu seramiklerin kulanım amacı ve yayılım alanı daha önceki yıllarda sistematik biçimde araştırılmadığından dolayı bu makalede tarafımızca incelenmiștir.

Çalışma, alan araştırması ve kütüphane incelemeleri şeklinde yürütülmüştür. Çalışmada Nahçıvan`ın Erken Tunç Çağı yerleşimlerinden ele geçen pişmiş topraktan yapılmış minyatür seramiklerden bahsedilmiş, onların biçimi, özelliği, kullanımı, yayılım alanı vb. incelenmiştir.

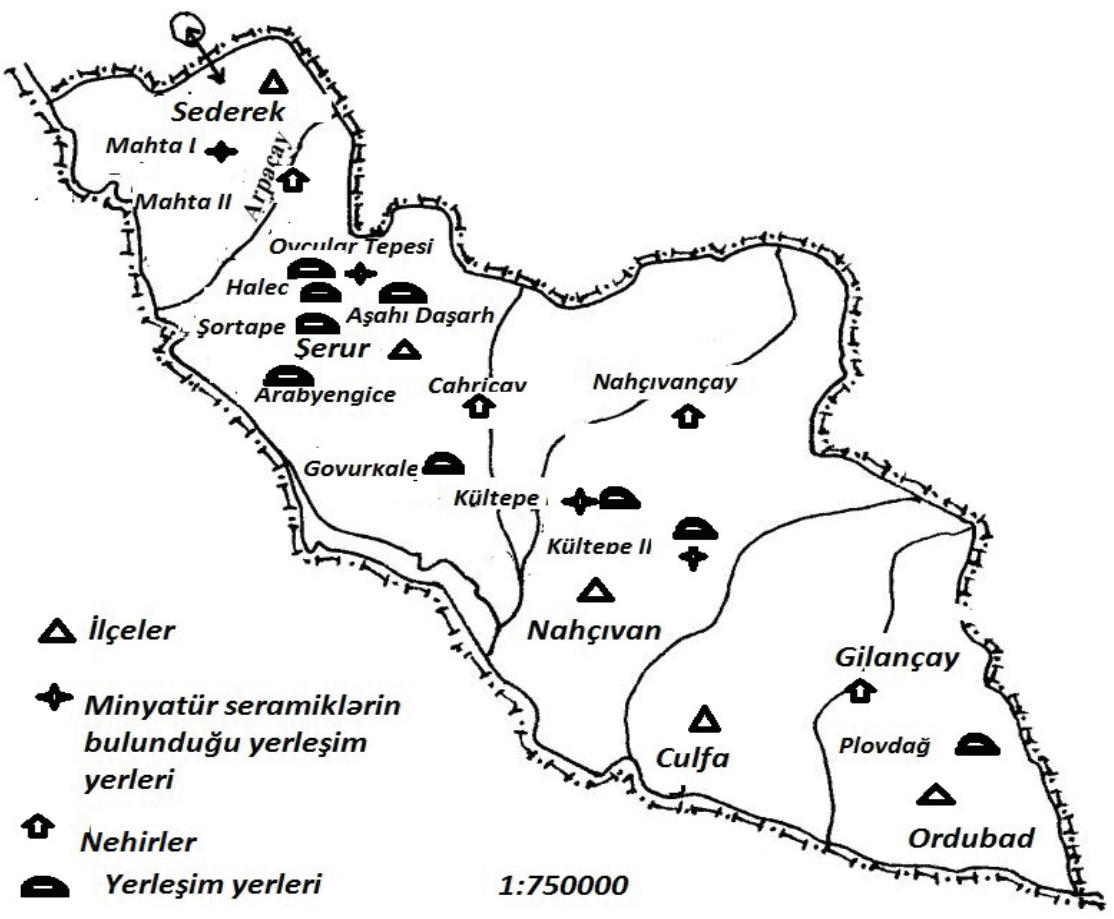

G. 1. Nahçıvan'ın Erken Tunç Çağı yerleşim yerleri'

1 Haritanın çizimi yazarın kendisine aittir. 


\section{Dairesel, Konik, Silindirik Biçimli Seramikler}

Nahçıvan'ın Erken Tunç Çağı'na tarihlenen Mahta I, Kültepe I, Kültepe II yerleşimlerinde minyatür seramikler bulunmuştur. Bulgular içerisinde dairesel, konik, silindirik biçimli seramiklere rastlanılmıştır (G. 2, G. 3). Dairesel biçimli seramiklerin bir grubunun üzerinde delik vardır. Çapları yaklaşık 2-9 cm, kalınlıkları 0,5-2 cm civarındadır. Bunların bir grubu kırık parçalardan oluşmaktadır. İnce ve iri kum karışımı olan kilden yapılmışlardır. Bir grubu basit şekildedir. Bazılarının üzerinde geometrik desenler çizilmiştir. Mahta I yerleşim yerinde bulunan bu tip bulgulardan birinin üzerinde insan gözünü ve burnunu yansıtan oyuklar yapılmıştır (G. 2, G. 6). Kültepe II yerleşim yerinde bulunan bu tip bulgulardan bazılarının üzerinde ise kazıma teknik yöntemi ile bitkisel motif çizilmiştir. ${ }^{2}$

Bu tip bulguların yayılım alanı konusunda yapılan araştırma sonucunda Nahçıvan'ın yanı sıra Azerbaycan'ın Kobustan ${ }^{3}$, Üzerliktepe ${ }^{4}$, Babaderviş ve İlanlıtepe ${ }^{5}$ yerleşim yerlerinde aynı bulguların bulunduğunu görmek olasıdır. Azerbaycan’ın yanı sıra dünyanın çeşitli bölgelerinde yer alan Kizanantkora ${ }^{6}$, Kunib ${ }^{7}$, Luki-Vriblevetski ${ }^{8}$, Yanıktepe ${ }^{9}, \mathrm{Ur}^{10}$ gibi arkeolojik yerleşimlerde de aynı tip minyatür seramikler ele geçmiştir.

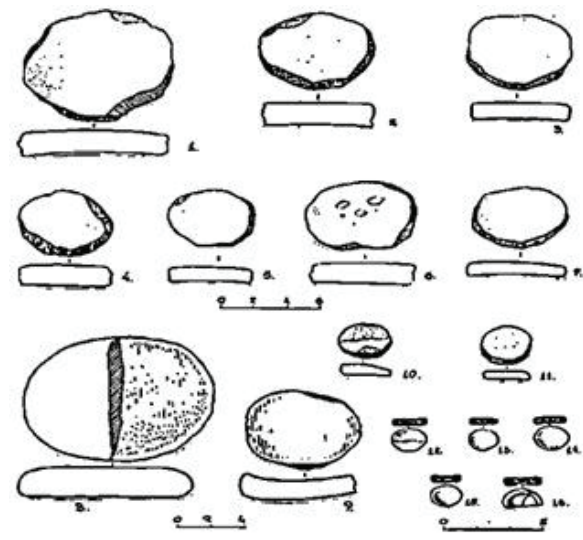

G. 2. Dairesel biçimli seramikler (Aşurov, Nahçıvanın İlk Tunc Devri Keramikası, 147)

2 Safar Aşurov, Nahçıvanin İlk Tunc Devri Keramikası (Bakü: Nafta-Press Yayınları, 2002), 58-59.

3 İsak Djafarzade, "Naskalnıye İzobrajeniya Kobıstana," Arkeolokiçeckiye İssledovaniya V Azerbaydjane (Bakü: Nauka Yayınları, 1965), 53.

4 Karina Kuşnareva, "Poceleniye Epoki Bronzı Na Kolme Uzerliktepe Okolo Akdama," MIA SSR (Moskva: Nauka Yayınları, 1957), 67: 2, ris. 20

5 İdeyal Narimanov, Kultura Drevneyşeko Zemledelçesko Skotovodçeskoko Naseleniya Azerbaydjana (Bakü: Nauka Yayınları, 1987), 228, ris. 32, 39.

6 Avalişvili Kikvidze, Rannebronzovoe Poceleniye Kizanant-Kora (Tbilici: Qosizzad Yayınları, 1972), 26, ris. 7.

7 Viktorovna Kotoviç, Verhniye Kunibckoye Pocelenie (Mahaçkala: Mahaçkala Yayınları, 1965), 181.

8 Sergey Bibikov, "Rannetripolckoye Poceleniye Luka-Vrublevski," MİA SSSR 38 (1953), 201

9 Kuşnareva , "Poceleniye Epoki Bronzı Na Kolme Uzerliktepe Okolo Akdama," 26, ris. 4 b.

10 İlqar Hüseynov ve Nigar Efendiyeva, Kadim Dünya Medeniyyeti (Bakü; Mars-Print NPM Yayınları, 2009), 108. 
2012, 2013, 2014 y1llarında yapılan kazılarda Mahta I arkeolojik yerleşiminde bu tip seramiklerin çeşitli biçimleri bulunmuştur. ${ }^{11}$ (G. 2) Bunların alt bölümü dairesel, üst bölümü silindirik biçimdedir. Yüksekliği 2,5 cm, dairesel bölümünün çap1 yaklaşık 1,5 cm'dir. Benzerleri şimdilik Nahçıvan'ın Erken Tunç Çağı yerleşimlerinde ele geçmiştir. Azerbaycan'ın Kalkolitik Çağı'na ait Leylatepe, Büyük Kesik ${ }^{12}$ gibi yerleşim yerlerinde bu tip seramikler bulunmuştur. Azerbaycan'ın yanı sıra Ubeyd kültürüne ait birçok arkeolojik yerleşimde de bu tip arkeolojik bulgular tespit edilmiştir. ${ }^{13}$ Azerbaycan'daki arkeolojik yerleşimlerden ele geçen örneklerin bazıları özelliğine göre Ubeyd kültürüne ait örneklerden farklılık göstermektedir.

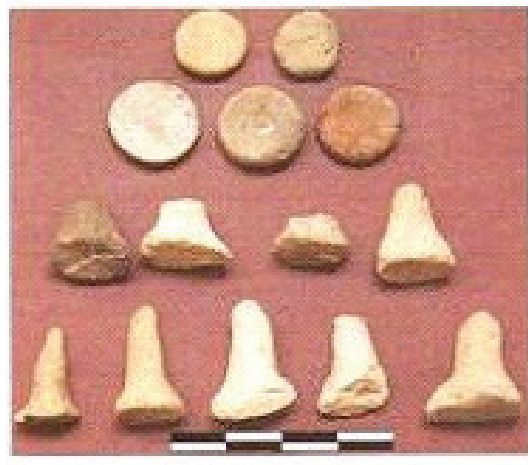

1
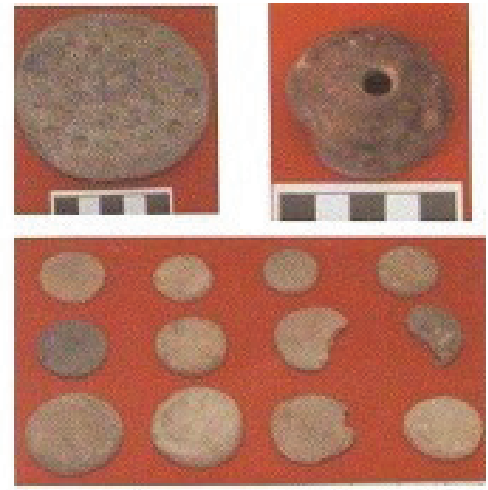

2

G. 3. Dairesel, silindirik biçimli seramikler: 1, 2- Mahta I (Aşurov vd., "Mahta Arkeoloji Ekspedisiyasının Tedkikatları", 106;-Aşurov vd., "Mahta Arkeoloji Ekspedisiyasının 2013-2014 y1l tetkikatlar1," 115)

Bu tip seramiklerin yayılım alanı ve anlamı konusunda farklı öneriler bulunmaktadır. R. Mekkenem'e göre, bu tip seramikler, “jeton (token)” olarak kullanılmıştır. ${ }^{14}$ H. Genouiilac'1n düşüncesine göre, bu seramik objeler gönderen kişinin sosyal statüsünü belirtmektedir. ${ }^{15}$ D. Smandt-Bessarat'ın düşüncesine göre, silindirik şekiller halk tarafından ekonomik ve kültürel ilişkiler sırasında ticarette kullanmışlardır. Disk biçimliler "koyun”, “kumaş”, “yün”; koni biçimliler “ekmek”, "baharat”; oval

11 Safar Așurov vd., "Mahta Arkeoloji Ekspedisiyasının Tedkikatları," Azerbaycanda Arkeoloji Tedkikatlar-2012, (Bakü: Nafta-Press Yayınları, 2013), 106; Safar Aşurov vd., "Mahta Arkeoloji Ekspedisiyasının 2013-2014-cü yıl Tedkikatlar1,” Azerbaycanda Arkeoloji tedkikatlar-2013-2014, (Bakü: Nafta-Press Yayınlar1, 2015), 115.

12 Vali Aliyev ve İdyal Narimanov, Kultura Severnoko Azerbaydjana V Epoki Pozdnoko Eneolita (Bakü: Nauka Yayınları, 2001), 51; İdyal Narimanov, Tufan Akundov ve Namik Aliyev, Leylatepe-Poseleniye, Tradiçii, Etap V Etno-Kulturnoy Istorii Yujnoko Kavkaza (Bakü: Nauka Yayınları, 2007), 52; Nacaf Müseyibli, Böyük Kesik Eneolit Devri Yaşayış Meskeni (Bakü: İlim Yayınları, 2007), 27.

13 Corc Lloyd, Arkeologiya Mesopotomii (Moskva: Nauka Yayınları, 1984), 51-52

14 Mecguenem, Roland, "Foulles De Suse 1929-1933 (Sur I Akrpolle Et La Ville Royale)," Memoires De La Mission Archeologigue De Perse XXV, (Paris: Leroux Yayınları, 1934), 193.

15 Henri Genouillac, Foulles De Telloh, Epogues Presaronigues, (Paris: Geuthner Yayınları, 1934 ), I : 28. 
biçimliler "yağ"' sembolize etmektedir. ${ }^{16}$ L. Brun ve F. Vallat'ın düşüncesine göre, silindirik biçimliler "1", disk biçimliler "10", balon biçimliler "100", küçük koni biçimliler "300", büyük koni biçimliler "1000" veya "3000" sayılarını belirtmektedir. ${ }^{17} \mathrm{Bu}$ gibi arkeolojik bulguları kilden bir zarfa koyarak gizli bilgileri bir yerden başka yere taşımışlardır. Zarfta olan bilgiyi öğrenmek için mührü kırarak, içindeki bilgiye ulaşmışlardır. İlk kez M.Ö. 3200 yılında Sümerler bu yöntemi kullanmışlardır. Bununla ilgili ilginç bir arkeolojik bulgu, ABD arkeologları tarafindan 1927-1931 yıllarında Irak'ın Yorgan Tepe olarak (Nuzi) adlandırılan arkeolojik yerleşim yerinde bulunmuştur. Çalışma sırasında yerleşimden M.Ö. 2000 yılına ait olan ve üzerinde Akkad çivi işaretleriyle çizilmiş seramik eserler bulunmuştur. İşaretlerde kırk sekiz baş küçük boynuzlu hayvanın (keçi ve koyunların) bir çobana verildiğini belirten kil zarfta silindirik biçimde kırk sekiz adet figür yer almaktadır. ${ }^{18}$ Şu an için yaklaşık 186 adet zarf bulunduğu bilinmektedir. Bunlardan 150`si İran'daki Susa ve Chogha Mish; 18 'i Irak’taki Uruk, Hafaci; 18 `i ise Suriye'deki Cebel Aruda, Habuba Kabira yerleşim yerlerinde bulunmuştur. ${ }^{19}$ İ. E. Kelb'in düşüncesine göre, binyıllar boyunca Ön Asya'nın çeşitli yerlerinde toplam ve birim sayılarında bu objeler kullanılmıştır. ${ }^{20}$ Araştırmacılardan S. H. Aşurov ve A. H. Alimirzeyev, bu tip seramiklerin sayılarla ilgili olmadığını belirtmiştir. Onların düşüncesine göre, 1929-1933 yıllarında Susa'da yapılan arkeolojik kazılarda bulunan bu tip otuz adet seramik eseri söz konusu buluntuların sayılar için kullanılmadığını kanıtlamaktadır. Aşurov ve Alimirzeyev, Mahta I yerleşim yerinde yapılan arkeolojik kazılar sonucu, Ön Asya'nın benzer yerleşimlerinde şehir tipli yerleşimlerinde olduğu gibi, Nahçıvan bölgesinde sosyal eşitsizliğin ve devlet geleneklerinin olduğunu kanıtlayan bu bulguların M.Ö. 3200 yılına kadar kullanıldığını belirtmiştir. ${ }^{21}$

Araştırmacılardan S. N. Bibikov ${ }^{22}$, R. M. Munçayev ${ }^{23}$, M. Cafarzade ${ }^{24}$, S. Aşurov ${ }^{25}$, V. Aliyev ' ${ }^{2}{ }^{26}$ düşüncesine göre, deliksiz yapılan disk biçimler oyun taşı olarak kullanılmıştır. M. Cafarzaden'in düşüncesine göre, disk biçimli objelerle "dama-dama" olarak adlandırılan oyunu oynamışlardır. S. H. Aşurov, bu tip bulgularla insanların

16 Denise Schmandt-Bessarat, "The Earliest Presursor Of Writting," Scifentic American 238/6 (1978), 39.

17 Alain Le Brun ve Francois Vallat, "L’origine de I'criture in a Susa," Cahiers de la Delagation Archeologigue Francause En Iran 8 (1978), 33; Francois Vallat, "The Most Ancient Scripts Of İran The Current Situation," World Archaelogy XVII/3 (1986), 344.

18 Al Oppenheim, "On an Operational Device in Mesopotomian Bureaucrary," Journal of Near Eastern Studies 18 (1959), 123.

19 Schmandt-Bessarat, "The Earliest Presursor Of Writting," 40.

20 İrina Kelb, Opıt İzuçeniya Pisma (Moskva: Nauka Yayınları, 1982), 325.

21 Safar Aşurov ve Allahverdi Almirzeyev, "Kür-Araz Medeniyyeti Cemiyyetinin İnzibati İdare Etmesine Dair Yini Tapıntılar," Azerbaycan Arkeologiyast ve Etnokrafiyası (Bakü: Nafta-Press Yayınları, 2013), 36.

22 Bibikov, "Rannetripolckoye Poceleniye Luka-Vrublevski," 201.

23 Rauf Munçayev, Kavkaz na Zare Epohi Bronzı (Moskova: Nauka Yayınları, 1975), 121.

24 Djafarzade, "Naskalnıye İzobrajeniya Kobıstana," 54.

25 Aşurov, Nahçıvanın Illk Tunc Devri Keramikası, 58.

26 Veli Aliyev, Azerbaycanda tunc devrinin boyalı kablar medeniyyeti (Bakü: İlim Yayınları, 1977), 96. 
“yedi taş" denilen oyunu oynadığını söylemiştir. Ayrıca günümüzde Nahçıvan'ın birçok köyünde çocukların bu tip bulgularla (taş, cam, seramik parçaları vb.) "yedi taş" denilen oyunu hala oynadıklarını söylemiştir. S. H. Aşurov üzeri delikli olan objeleri iki gruba ayırmıştır. Nispeten küçük yapılmış, üzerinde iki delik olanların süs asma (Mahta I, Kültepe II yerleşim yerlerinde bulunmuştur); ortasında bir delik olanların, nispeten büyük yerleşimlerde (Kültepe I, Kültepe II yerleşim yerlerinde bulunmuştur) kullanılan dokuma aleti olduğunu söylese de, bu dokuma aletinin nasıl çalıştığını belirtmemiştir. V. H. Aliyev, bu tip bulguların pişmiş toprağın yanı sıra iri başlı hayvanların kemiklerinden de yapıldığını ve dokuma aleti olarak kullanıldığını söylemiştir. ${ }^{27}$

\section{Tekerlekler}

Nahçıvan bölgesi'nin Erken Tunç Çağı yerleşimlerinde bulunmuş dairesel biçimli seramiklerden bir grubunu tekerlekler oluşturmaktadır. Mahta I ${ }^{28}$, Kultepe ${ }^{29}$, Kultepe $\mathrm{II}^{30}$, Ovçular Tepesi ${ }^{31}$ yerleşimlerinden bu tip seramik eserleri bulunmuştur. Bunların benzerleri Telmankend ${ }^{32}$, Babaderviş ${ }^{33}$, Valikend ${ }^{34}$, Sarıtepe ${ }^{35}$, Leylatepe, Büyük Kesik, Kalayeri, Poylu II ${ }^{36}$, Polutepe ${ }^{37}$, Mingeçevir ${ }^{38}$, Kobustan ${ }^{39}$, Yanık Tepe ${ }^{40}$, Göyte$\mathrm{pe}^{41}$, Trialett ${ }^{42}$ yerleşimlerinde ve Anadolu ${ }^{43}$, Altay ${ }^{44}$ ve dünyanın farklı bölgelerinde ${ }^{45}$ bulunmuştur. Tüm pişmiş toprak tekerleklerin ortası her iki tarafa doğru kabarık

27 Aliyev, Azerbaycanda Tunc Devrinin Boyal, Kablar Medeniyyeti, 96

28 Aşurov, vd., "Mahta Arkeoloji Ekspedisiyasının 2013-2014-cü yıl Tedkikatları,” 119.

29 Osman Abibullayev, Eneolit İ Bronzı Na Territorii Nakiçevanskoy ASSR (Bakü: Nauka Yayınları, 1982), 139.

30 Abbas Seyidov, Pamyatniki Kura-Arakskoy Kulturı Nakiçevana (Bakü: Bilig Yayınlar, 1993), 56.

31 Veli Bahşaliyev, Caterina Marro ve Safar Aşurov, "Ovçulartepesinde Arkeoloji Tedkikatlar," Azerbaycanda Arkeoloji Tedkikatlar-2012 (Bakü: Nafta Press Yayınları, 2013), 348.

32 Fahreddin Mahmudov, Kultura Yuka-Vostoçnoko Azerbaydjana V Epohi Bronzı I Ranneko Jeleza (Baku: Nafta-Pres Yayınları, 2008), 39.

33 Kudrat İsmaylov, "Klinyannıye Fiqurki İz Poseleniya Babaderviş Bliz Korod Kazah Azerbaydjanskoy SSR," Dokladı AN. Azerb. SSR 10 (1962), 96, ric. 6, 7.

34 Viktorovna Kotoviç, "Noviye Arkeolokiçeskiye Pamyatniki Dakestana,” MAD (1959), 124, tab.1, 6.

35 İdyal Narimanov, "Sarıtepe Yaşayış Yerinde Arkeoloji Kazıntılar,” Azerbaycan SSR Elmler Akademiyasının Haberleri. Tarih, Felsefe, Hüquq Serisı 3 (1959), 34-35.

36 Firiza Muradova, Kobustan Tunc Devrinde (Bakü: İlim Yayınları, 1979), 85.

37 Tufan Akundov, "Pamyatniki Mukanskoy Stepi İ Predposılka Rasseleniya Rannıy Zemledelçev Na Yujnom Kafkaze V Epoki Neolita-Eneolita". Startum Plus (2011), 224-225.

38 Kardaşhan Aslanov, Raqim Vahidov ve Krikori İone, Drevnıye Minkeçaur (Bakü: Nauka Yayınları, 1959), 130 , ris. 100-101.

39 Muradova, Kobustan Tunc Devrinde, 53.

40 Corc Burney, “The Excavations At Yanik Tepe, Azerbaijan, 1961 Second Preliminary Report," Irak 24/2 (1962), tab. XXIV.

41 Burton Brown, Excavations In Azerbaijan 1948 (London: Murray, 1951), 48, fig. 13.

42 Boris Kuftin, Arkeolokiçeskiye Raskopki V Trialetti (Tblisi: AN Kruzinskoy SSR Yayınları, 1941), 95.

43 Burney, “The Excavations At Yanik Tepe, Azerbaijan, 1961 Second Preliminary Report,” 18-20.

44 Mixail Kryaznov, "Kultura İ İskustvo Pannıy Koçevnikov Altaya," Pervobıtnaya kultura 2 vip (Moskova: Nauka Yayınları, 1956), 18.

45 Baxtıyar Tuncay, Kurkanlarda Yatan Mitoloji Tefekkür ve Ginetik Tarihimiz (Bakü: İlm ve Tahsil Yayınları, 2018), 102, 106,150, 187, 321. 
yapılmış, yüzeyi iyi açkılanmıştır (G. 4). Buluntuların birçoğunun tekerleğe geçen dingil (ok) bölümü ahşaptan yapıldığı için doğal aşınma sonucu dağılmış, günümüze kadar sağlam kalmamıştır.

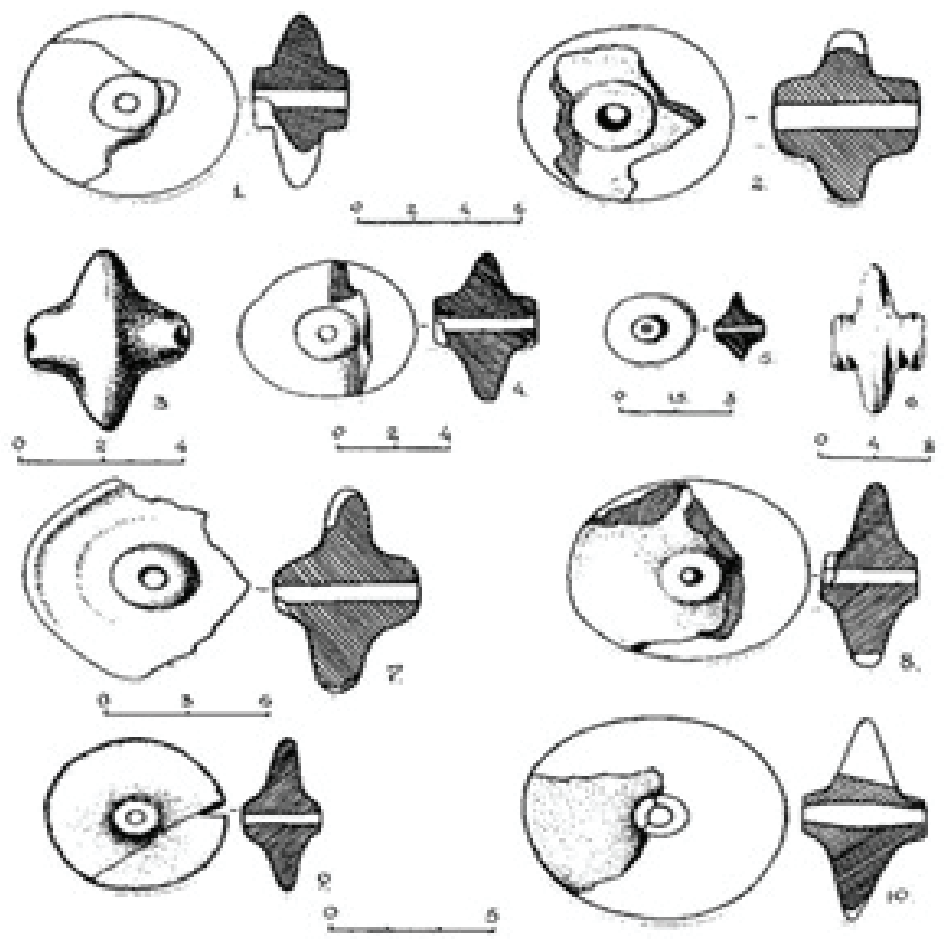

G. 4. Kil tekerlekler (Aşurov, Nahçıvanın İlk Tunc Devri Keramikası, 149)

\section{Araba Figürleri}

Azerbaycan'ın Erken Tunç çağı yerleşimlerin bazılarında tekerleğin yanı sıra kilden yapılan araba figürleri de bulunmuştur (G. 5). Mingeçevir ve Kobustan'dan ele geçen bu tip minyatür arabaları iki tekerleklidir. Anadolu'nun eski arkeolojik yerleşimlerinden bulunanların birçoğuysa dört tekerlidir. Bu tekerlekli minyatür arabaların bazıları şimdi Diyarbakır, Gaziantep, Adana müzelerinde sergilenmektedir. ${ }^{46}$ 


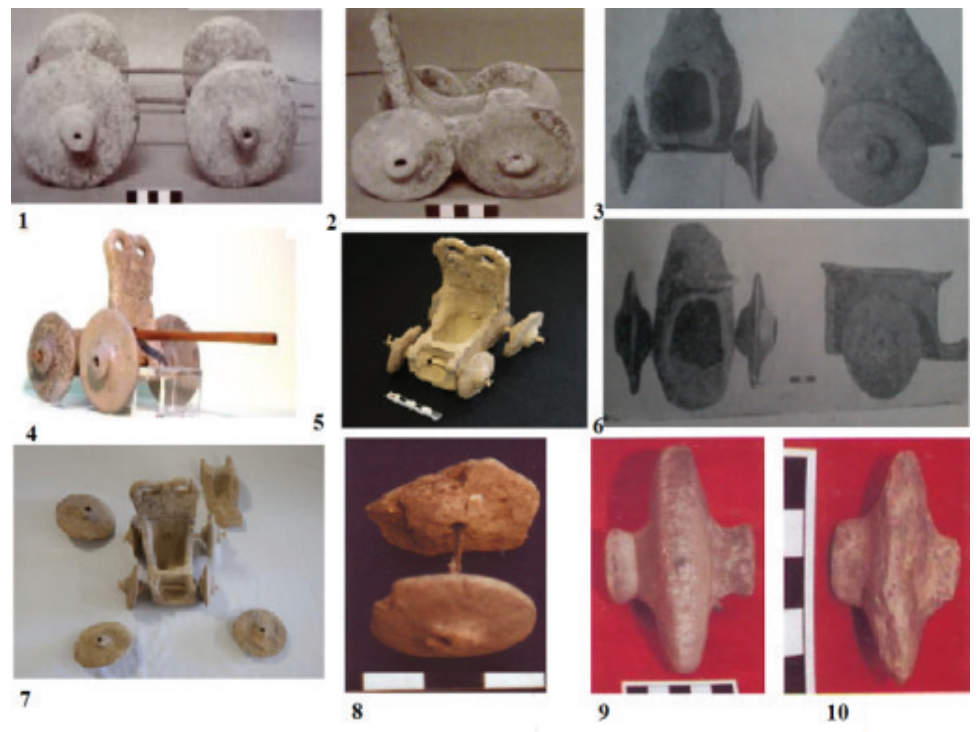

G. 5. Pişmiş topraktan yapılmış minyatür tekerlek ve arabalar: 1, 2-Anadolu (San, Diyarbakıı Müzesinde Yer Alan İki Adet Pişmiş Toprak Araba Modeli, 605, res. 1, 3); 3, 6-Mingeçevir (Aslanov, Vaidov ve İone, Drevnıye Minkeçaur, 130, 131); 4-Gaziantep (Çetinkaya, M.Ö. 3. Binyılın Başlarından M.Ö. 1. Binyılın Ortalarına Kadar Anadolu Arabaları, 159); 5, 7- Şanlıurfa (http://aa.com.tr/tr/kultur-sanat/5-bin-yillik-oyuncak-at-arabasi-bulundu/924641); 8-Ovçulartepesi

(Bahşeliyev, Marro ve Aşurov, Ovçulartepesinde Arkeoloji Tedkikatlar, 348); 9-10-Mahta I

(Aşurov vd., "Mahta Arkeoloji Ekspedisiyasının 2013-2014-cü yıl Tedkikatları," 121)

Minyatür tekerlek ve arabaların yerleşim yerlerinin yanı sıra nekropollerden bulunması, onların tesadüfen yapılmadığını, belirli mantıksal anlamının olduğunu kanıtlamaktadır. Düşüncemizi kanıtlamak için tarihe baktığımızda minyatür tekerlek ve arabaların "Bir hayvan koşma kültürü”"47, "Atlı araba kültürü” " 8 ile bağ kurması konusunda kaynaklarda çeşitli bilgiler bulunmaktadır. Tekerleğin ilk kez ne zaman keşfedildiği konusunda birçok araştırmacının farklı düşüncesi vardır. İngiliz arkeologlarından Spencer ve Kavrada, Mezopotamya'da yaptıkları arkeolojik araştırmalar sırasında buldukları taş üzerinde yapılmış bir kabartma resmini kanıt göstererek tekerleğin ilk kez M.Ö. 5000 yılında Mezopotamya'da keşf edildiğini belirtmişlerdir. ${ }^{49}$ Araştırmacılar ilk zamanlar bu arkeolojik bulgunun tekerlek olduğunu kesin tespit edememişlerdir. Onun seramik çarkına ait olduğunu düşünmüşlerdir. Sonraki dönemde yaptıkları arkeolojik araştırmalar sonucu bu bulgunun tekerlek olduğunu anlaşılmıştır. Onların düşüncesine göre M.Ö. 3500 yılında Sümerler arabanın yükünü taşımak için tekerlek kullanmışlardır. Spencer ve Kavrada'dan sonra İngiliz araştırmacı Volle de bu konuda araştırma yapmıştır. Çalışmaları sırasında Mezopotamya'da M.Ö. 2950 yılına ait yeni bir tekerlek bulunmuştur.

47 Baheddin Ögel, İslamiyetten Önce Türk Kültür Tarihi (Orta Asya Kaynak ve Buluntularına Göre) (Ankara: Türk Tarih Kurumu Yayınları, 2003), 395.

48 Şayan Ulusan, “Türk Kültüründe At Arabası (At Arabalarının Dili)," Bilig 32 (2005), 166.

49 Ural Akbulut, Tekerlekli arabayı Sümerler 5000 yıl önce keşfetti, erişim 1 Mart 2018.

http://www.uralakbulut.com.tr/wp-content/uploads/2012/12/tekerlekliaraba.pdf. 
Spencer, Kavrada ve Volle'nin araştırmaları sonucunda ilk çağlarda arabaların iki tekerlek olduğu ve Sümerler'in iki tekerlekli arabayı M.Ö. 2800 yılında savaşta kullandığı düşünülmektedir. M.Ö. 2500 yılında Sümerler iki tekerlek yerine dört tekerlekli arabayı daha çok kullanmışlardır. Her iki tip tekerleği ilk dönemde parmaksız yapmışlardır. M.Ö. 2000 yılındaysa parmaklı biçimde olanı yapmışlardır. ${ }^{50}$ Mezopotamya'nın yanısıra Mısır, Hitit kültürlerinde de çok sayıda araba figürü bulunmuştur. ${ }^{51}$

İngiliz arkeologların yanısıra başka araştırmacılar da tekerleğin ve arabanın ilk kez ne zaman keşfedildiği konusunda çeşitli fikirler ortaya atmıştır. Araştırmacılardan bazıları tekerlek ve arabanın ilk kez M.Ö. IV binyılda Urmiye-Van bölgesinde keşf edildiğini ve M.Ö. 3000-2000 arasında buradan dünyanın diğer bölgelerine yayıldığını söylemişlerdir. ${ }^{52}$ Bir grup araştırmacı Çin kaynaklarına dayanarak onların ilk kez M.Ö. 2000800 yıllarında Türkler tarafından kullanıldığını belirtmişlerdir. ${ }^{53}$ Kaşgarlı Mahmud'un Divanü Lugati't-Türk eserinde ${ }^{54}$ ve Fazlullah Raşideddin'in Ŏguzname'sinde bulunan bilgi de Çin kaynaklarında olan bilgiyle mantıksal bağlılık oluşturmaktadır. Fazullah Reşideddin'in Oğuzname adlı eserinde bahsedilen bilgi şu şekildedir:

“(...) Diğer bir kavim de, düşmanları yağma edip ganimet, olcay alındığında, hayvanlar bunları taşımak için yetişmediğinden "Kanglı”lar yaptılar. Bundan evvel tekerlek yoktu, (arabayl) ilk defa bunlar yaptılar. Levazım, ağırlık ve "olcay”ları bunun üzerine koyarak taşıdılar. Oğuz bundan dolayı onlara "Kanglı” yani arabacılar ismini verdi. " 55

Mezopotamya gibi Azerbaycan'da da minyatür tekerleğin tarihi yaklaşık M.Ö. 5000 yılına denk gelmektedir. Azerbaycan'daki Kalkolitik Çağı'na ait (M.Ö. VI-IV. binyıllar) Polutepe ${ }^{56}$, Leylatepe, Büyük Kesik, Kalayeri, Poylu II ${ }^{57}$, Kültepe I ${ }^{58}$ arkeolojik yerleşimlerinden bu çağa ait çok sayda kil minyatür tekerlek bulunmuştur. Araştırmacı Nacaf Müseyibli, Azerbaycan'ın Kalkolitik Çağ1 yerleşimlerinde (Leylatepe, Büyük Kesik, Kalayeri, Poylu II, Polutepe) bulunan kil tekerleği örnek göstererek arabada kullanılması ve Hint-Avrupa bölgesinden Kafkasya’ya yayılması konusundaki düçüncelerin ${ }^{59}$ hiçbir bilimsel dayanağı olmadığını söylemiştir. ${ }^{60}$

$50 \mathrm{http}: / /$ www.tarihiolaylar.com/tarihi-olaylar/tekerlek-156. erişim 1 Mart 2018.

51 http://dunyaharptarihi.blogspot.com/2012/02/savaslari-degistiren-50-silah-6-savas.html.

52 Tuncay, Kurkanlarda Yatan Mitoloji Tefekkür ve Ginetik Tarihimiz, 104.

53 Beihai, Su, Xinjiang Yan Hua (Urumchi: Kinjiang Mei Shu She Ying Chu Ban She Yayınlar1, 1994), 523-524.

54 Faruk Sümer, Türklerde Atçıllk ve Binicilik (Ankara: Türk Dünyası Araştırmaları Vakfı Yayınları, 1983), 11.

55 Zeki Veli Togan, Oğuz Destanı. Reşideddinin Oğuznamesi (İstanbul: Enderun Kitabevi Yayınları, 1982), 17.

56 Akundov, "Pamyatniki Mukanskoy Stepi İ Predposılka Rasseleniya Rannıy Zemledelçev Na Yujnom Kafkaze

V Epoki Neolita-Eneolita," 224-225.

57 Müseyibli, Böyük Kesik Eneolit Devri Yaşaylş Meskeni, 84.

58 Narimanov, İdyal, Kultura Drevneyşeko Zemledelçesko Skotovodçeskoko Naseleniya Azerbaydjana (Baku: Nauka Yayınları, 1987), 60.

59 Laszlo Rasonyi, Tarihte Türklük (Ankara: Türk Kültürünü Araştırma Enstitüsü Yayınları, 1971), 16.

60 Nacaf Müseyibli, Leylatepe Medeniyyetinin Kabir Abideleri Ve Defn Adetleri (Bakü: Nafta-Press Yayınlar1, 2014), 85 . 


\section{Sonuç}

Konuyla ilgili yaptı̆̆ımız karşılaştırmalı araştırma sonucunda tespit ettiğimiz bulguları şu şekilde belirtebiliriz: Erken Tunç Çağı'nda seramik sanatının gelişmesi sonucu seramik eserlerinin hem kalitesi, hem de çeşitliliği artmıştır. Biçim ve özelliklerine göre seramik eserlerin hepsi aynı değildir. Bunların birbirinden farklı olmasının nedeni hepsinin aynı sanatçı atölyesinden çıkmadığı, ayrı ayrı seramikçiler tarafından yapılmış olmasıdır. Seramik eserleri gibi minyatür pişmiş toprak objeler de tesadüfen yapılmamış ve belli amaçlar doğrultusunda kullanılmıştır.

Dairesel biçimli minyatür seramiklerin bir grubu, Erken Tunç Çağı'nda Nahçıvan'da sosyal eşitsizliğin olduğunu kanıtlayan arkeolojik bulgulardır. Bunları ekonomik ve kültürel ilişkiler sırasında eserlerin, ürünlerin veya malzemenin sayısını ve türünü belirlemek için kullanmışlardır. Bir diğer grup obje ise iş aletleri ve oyun taşlarıdır. Azerbaycan'ın Kobustan, Üzerliktepe, Babaderviş ve İlanlıtepe yerleşim yerleriyle dünyanın çeşitli bölgelerinde yer alan arkeolojik yerleşimlerde (Kizanantkora, Kunib, Luki-Vriblevetski, Yanıktepe, Ur vb.) aynı tip minyatür seramikler ele geçmiştir. Nahçıvan'daki Erken Tunç Çağı'nda ait arkeolojik yerleşimlerden ele geçen örneklerin bazıları özelliğine göre dünyanın çeşitli bölgelerinde bulunanlardan farkl1lık göstermektedir.

Dünyanın her tarafında tekerliğin keşfi ve teknik yöntemi aynı olmuştur. Tekerlek keşfedilene kadar insanlar taşınması kolay olan yükleri sırtlarında ve omuzlarında taşımışlardır. Ağır ve büyük yükleri omuzlarında ve sırtlarında taşıyamadıkları için çok emek ve zaman gerektiren çeşitli ilkel teknik yöntemler kullanmışlardır. Dairesel biçimli minyatür seramikler gibi pişmiş topraktan yapılan tekerlek ve arabalar da özelliğine göre dünyanın çeşitli bölgelerinde bulunanlardan farklılık göstermektedir. Tekerlek ve arabaların yerleşim yerlerinin yanı sıra nekropollerden bulunması, onların tesadüfen yapılmadığını, belirli mantıksal anlamının olduğunu kanıtlamaktadır. Tekerliğin keşfi, arabanın keşfine ortam hazırlamıştır. Arabanın keşfinin insanların yaşam tarzına etkisi de büyük olmuştur. İnsanlar atın yanısıra öküzü de arabaya koşarak ondan ekonomik-kültürel ilişkilerde, savaşta vb. amaçlar doğrultusunda yararlanmışlardır. Dünyanın pek çok yerinde olduğu gibi Nahçıvan`da da arabanın çeşitli yöntemlerde kulanılması sonucu “Araba kültürü”nün oluşum süreci başlamıștır. Tarihte at koşulmuş arabayı en çok Türkler kullanmışlardır. Türklerin atı binek hayvanı gibi kullanması onların hareket özgürlüğünü daha çok artırmış, daha geniş topraklara yayılmalarına ve sahip olmalarına ortam sağlamıştır. Mezopotamya gibi Azerbaycan'da da Kalkolitik Çağı'na ait (M.Ö. VI-IV. binyıllar) yerleşim yerlerinde (Polutepe, Leylatepe, Büyük Kesik, Kalayeri, Poylu II, Kültepe I vb.) çok sayıda minyatür tekerleğin ve arabanın bulunması Azerbaycan'da da onların tarihinin yaklaşı M.Ö. 5000 yılını kapsadığını kanıtlamaktadır. Tarihte at koşulmuş arabayı en çok Türklerin kullanması, Azerbaycan'da onların tarihinin yaklaşık M.Ö. 5000 yılını kapsaması “Araba 
kültürü’nün Hint-Avrupa bölgesinden Kafkasya’ya yayılması konusunda düşüncelerin hiçbir bilimsel dayanağı olmadığını kanıtlamaktadır.

Hakem Değerlendirmesi: Dış bağımsız.

Çıkar Çatışması: Yazar çıkar çatışması bildirmemiştir.

Finansal Destek: Yazar bu çalışma için finansal destek almadığını beyan etmiştir.

Peer-review: Externally peer-reviewed.

Conflict of Interest: The author has no conflict of interest to declare.

Grant Support: The author declared that this study has received no financial support.

\section{Kaynakça/References}

Abibullayev, Osman. Eneolit İ Bronzı Na Territorii Nakiçevanskoy ASSR. Baku: Nauka Yayınları, 1982.

Akundov, Tufan. "Pamyatniki Mukanskoy Stepi İ Predposılka Rasseleniya Rannıy Zemledelçev Na Yujnom Kafkaze V Epoki Neolita-Eneolita.” Startum Plus (2011): 220-225.

Aliyev, Veli. Azerbaycanda Tunc Devrinin Boyalı Kablar Medeniyyeti. Bakü: İlim Yayınları, 1977.

Aliyev, Vali ve İdyal Narimanov. Kultura Severnoko Azerbaydjana V Epoki Pozdnoko Eneolita. Bakü: Nauka Yayınları, 2001.

Aslanov, Kardaşhan, Raqim Vahidov ve Krikori İone. Drevnıye Minkeçaur. Bakü: Nauka Yayınları, 1959.

Aşurov, Safar. Nahçıvanın İlk Tunc Devri Keramikası. Bakü: Nafta-Press Yayınları, 2002.

Aşurov, Safar ve Allahverdi Almirzeyev. "Kür-Araz Medeniyyeti Cemiyyetinin İnzibati İdare etmesine Dair Yini Tapıntılar.” Azerbaycan Arkeologiyası ve Etnokrafiyası. Bakü: Nafta-Press Yayınları, 2013, 34-39.

Aşurov, Safar, Veli Bahşeliyev, Sevinc Hüseynova ve Fidan Aliyeva. "Mahta Arkeoloji Ekspedisiyasının Tedkikatları.” Azerbaycanda Arkeoloji Tedkikatlar-2012. Bakü: Nafta-Press Yayınları, 2013, 100-108.

Aşurov, Safar, Sevinc Hüseynova, Fidan Aliyeva, Elvin Aliyev, Kamal Azizov, Vüsale Kasımlı ve Arzu Abdullayeva. "Mahta Arkeoloji Ekspedisiyasının 2013-2014-cü yıl Tedkikatları." Azerbaycanda Arkeoloji Tedkikatlar-2013-2014. Bakü: Nafta-Press Yayınları, 2015, 114-121.

Ögel, Baheddin. İslamiyetten Önce Türk Kültür Tarihi (Orta Asya Kaynak ve Buluntularına Göre). Ankara: Türk Tarih Kurumu Yayınları, 2003.

Bahşaliyev, Veli, Caterina Marro ve Safar Aşurov. “Ovçulartepesinde Arkeoloji Tedkikatlar.” Azerbaycanda arkeoloji tedkikatlar-2012. Bakü: Nafta Press Yayınları, 2013, 343-349.

Beihai, Su. Xinjiang Yan Hua. Urumchi: Kinjiang Mei Shu She Ying Chu Ban She. Yayınları, 1994.

Bibikov, Sergey. "Rannetripolckoye Poceleniye Luka-Vrublevski.” MİA SSSR 38 (1953): 190-205.

Brown, Burton. Excavations In Azerbaijan 1948. London: Murray Yayınlar1, 1951.

Burney, Corc. “The Excavations At Yanik Tepe, Azerbaijan, 1961 Second Preliminary Report.” Irak 24/2 (1962): 134-152.

Çetinkaya, Cöknur. "M.Ö. 3. Binyılın Başlarından M.Ö. 1. Binyılın Ortalarına Kadar Anadolu Arabaları.” Doktora Tezi, Adnan Menderes Üniversitesi, 2012 
Djafarzade, İsak. "Naskalnıye İzobrajeniya Kobıstana." Arkeolokiçeckiye İssledovaniya V Azerbaydjane. Bakü: Nauka Yayınları, 1965, 52-57.

Henri, Genouillac ve Foulles De Telloh. Epogues Presaronigues. Paris: Geuthner Yayınları, 1934.

Hüseynov, İlqar ve Nigar Efendiyeva. Kadim Dünya Medeniyyeti. Bakü: Mars-Print NPM Yayınları, 2009.

İsmaylov, Kudrat, "Klinyannıye Fiqurki İz Poseleniya Babaderviş Bliz Korod Kazah Azerbaydjanskoy SSR.” Dokladı AN. Azerb. SSR 10 (1962): 95-99.

Kelb, İrina. Opıt İzuçeniya Pisma. Moskva: Nauka Yayınları, 1982.

Kikvidze, Avalişvili. Rannebronzovoe Poceleniye Kizanant-Kora. Tbilisi: Qosizzad Yayınları, 1972.

Kotoviç, Viktorovna. "Noviye Arkeolokiçeskiye Pamyatniki Dakestana.” MAD (1959): 121-126.

Kotoviç, Viktorovna. Verhniye Kunibckoye Pocelenie. Mahaçkala: Dak FAN SSR Yayınlar 1965.

Kryaznov, Mixail. "Kultura İ İskustvo Pannıy Koçevnikov Altaya.” Pervobitnaya kultura. 2 cilt. Moskova: Nauka Yayınları, 1956, 9-22.

Kuftin, Boris. Arkeolokiçeskiye Raskopki V Trialetti. Tbilisi: AN Kruzinskoy SSR Yayınları, 1941.

Kuşnareva, Karina. “Poceleniye Epoki Bronzı Na Kolme Uzerliktepe Okolo Akdama.” MİA SSR 67, 21-25. Moskva: Nauka Yayınları, 1957.

Le Brun, Alain ve Francois Vallat. "L’origine de I'criture in a Susa." Cahiers de la Delagation Archeologigue Francause En Iran 8 (1978): 11-59.

Lloyd, Corc. Arkeologiya Mesopotomii. Moskva: Nauka Yayınları, 1984.

Mahmudov, Fahreddin. Kultura Yuka-Vostoçnoko Azerbaydjana V Epohi Bronzı İ Ranneko Jeleza. Bakü: Nafta-Pres Yayınları, 2008.

Mecguenem, Roland. "Foulles De Suse 1929-1933 (Sur I'Akrpolle Et La Ville Royale)." Memoires De La Mission Archeologigue De Perse XXV. Paris: Leroux Yayınları, 1934, 177-237.

Munçayev, Rauf. Kavkaz Na Zare Epohi Bronzı. Moskova: Nauka Yayınları, 1975.

Muradova, Firiza. Kobustan Tunc Devrinde. Bakü: İlim Yayınları, 1979.

Müseyibli, Nacaf. Böyük Kesik Eneolit Devri Yaşayış Meskeni. Bakü: İlim Yayınları, 2007.

Müseyibli, Nacaf. Leylatepe Medeniyyetinin Kabir Abideleri ve Defn Adetleri. Bakü: Nafta-Press Yayınları, 2014.

Narimanov, İdyal. "Sarıtepe Yaşayış Yerinde Arkeoloji Kazıntılar." Azerbaycan SSR Elmler Akademiyasının Haberleri. Tarih, Felsefe, Hüquq Serisi 3 (1959): 37-40.

Narimanov, İdyal. Kultura Drevneyşeko Zemledelçesko Skotovodçeskoko Naseleniya Azerbaydjana. Bakü: Nauka Yayınları, 1987.

Narimanov, İdyal, Tufan Akundov ve Namik Aliyev. Leylatepe-Poseleniye, Tradiçii, Etap V EtnoKulturnoy Istorii Yujnoko Kavkaza. Bakü: Nauka Yayınları, 2007.

Oppenherm, Al. "On an Operational Device in Mesopotomian Bureaucrary." Journal of Near Eastern Studies 18 (1959): 121-128.

Rasonyi, Laszlo. Tarihte Türklük. Ankara: Türk Kültürünü Araştırma Enstitüsü Yayınları, 1971.

San, Oya. "Diyarbakır Müzesinde Yer Alan İki Adet Pişmiş Toprak Araba Modeli." Altan Çilingiroğlu'na Armağan Yukarı Denizin Kıyısında Urartu Krallığı'na Adanmış Bir Hayat. İstanbul: Arkeoloji ve Sanat Yayınları, 2009, 599-605. 
Schmandt-Bessarat, Denise. "The Earliest Presursor Of Writting." Scifentic American 238/6 (1978): $38-47$.

Seyidov, Abbas. Pamyatniki Kura-Arakskoy Kulturı Nakiçevana. Bakü: Bilig Yayınları, 1993.

Sümer, Faruk. Türklerde Atçılık ve Binicilik. Ankara: Türk Dünyası Araştırmaları Vakfı Yayınları, 1983.

Togan, Zeki Veli. Oğuz Destani. Reşideddinin Oğuznamesi. İstanbul: Enderun Kitabevi Yayınları, 1982. Tuncay, Bahtıyar. Kurkanlarda Yatan Mitoloji Tefekkür ve Ginetik Tarihimiz. Bakü: İlm ve Tahsil Yayınları, 2018.

Ulusan, Şayan. “Türk Kültüründe At Arabası (At Arabalarının Dili).” Bilig 32 (2005): 165-178.

Vallat, Francois. "The Most Ancient Scripts Of İran The Current Situation." World Archaelogy XVII/3 (1986): 335-347.

https://www.aa.com.tr/tr/kultur-sanat/5-bin-yillik-oyuncak-at-arabasi bulundu/924641\#, 5 bin y1llik oyuncak at arabası bulundu. Erişim 1 Mart 2018.

http://www.tarihiolaylar.com/tarihi-olaylar/tekerlek-156. Erişim 1 Mart 2018.

Ural Akbulut, Tekerlekli Arabayı Sümerler 5000 Y1l Önce Keşfetti. Erişim 1 Mart 2018.

http:/www.uralakbulut.com.tr/wp-content/uploads/2012/12/tekerlekliaraba.pdf. Erişim 1 Mart 2018.

Dünya Harp Tarihi. Savaşları değiştiren 50 Silah (6) / Savaş Arabası. Erişim 1 Mart 2018.

http://dunyaharptarihi.blogspot.com/2012/02/savaslari-degistiren-50-silah-6-savas.html 
